\title{
SARS: Consequences for nurses, intensive care units and the health care system in Hong Kong
}

Violeta Lopez, RN, MNA, MPET, PhD, FRCNA, Professor, The Nethersole School of Nursing, The Chinese University of Hong Kong, Shatin, New Territories, Hong Kong Yuen Ching (Jonathan) Wong, RN, BN, M.Soc.Sc. Intensive Care Unit, United Christian Hospital, 130 Hip Wo Street, Kwun Tong, Kowloon, New Territories, Hong Kong Keung Sum Chan, RN, MHA, MN, Intensive Care Unit, United Christian Hospital, 130 Hip Wo Street, Kwun Tong, Kowloon, New Territories, Hong Kong

E-mail: violeta@cuhk.edu.hk

Key words: coronavirus Hong Kong intensive care unit severe acute respiratory syndrome SARS

\section{SUMMARY \\ * The outbreak of Severe Acute Respiratory Syndrome (SARS) in Hong Kong had a devastating effect on the lives of the public and health care professionals. \\ * The agent that causes SARS is a new coronavirus, unlike any other known human or animal virus in the coronavirus family. \\ * The rate of deterioration of patients with SARS is alarmingly high with many requiring intensive care. \\ * Planning for future outbreaks of SARS requires a collaborative effort.}

\section{EPIDEMIOLOGY OF SARS}

March 2003 saw the beginning of an outbreak of atypical pneumonia in Hong Kong, later known as severe acute respiratory syndrome (SARS). As of July 18, 2003, there were 1,755 reported cases (including 386 health care workers and medical students), and 299 deaths (including eight health care professionals) in Hong Kong (Department of Health, 2003). The outbreak of SARS in Hong Kong began when a Chinese physician from Guangdong Province, China, who cared for patients with pneumonia and had himself been infected, travelled to Hong Kong to visit his relatives. He stayed in a hotel and a week later was admitted to the hospital with complaints of fever and respiratory symptoms and subsequently died. He infected his family members, 12 other hotel guests, and health care workers and patients who were in the same ward where he was admitted. The 12 hotel guests went back to their respective countries (Canada, Vietnam, Singapore) and infected their family members and other close contacts (Centers for Disease Control and Prevention (CDC), 2003a; Wong \& Hui, 2003).

One of the hotel guests was later admitted to a Hong Kong hospital with febrile illness and was diagnosed with right upper lobe pneumonia. He was treated with antibiotics and nebulised salbutamol and recovered. Six days after his treatment, 18 health care workers from the same ward reported having the same symptoms (Tomlinson \& Cockram, 2003). The infection subsequently spread to another 69 health care workers and 16 medical students in the same hospital, including the intensive care unit (ICU) and accident and emergency department (Lee et al., 2003).

\section{PATHOPHYSIOLOGY OF SARS}

On April 19, the World Health Organisation (WHO, 2003) reported that the agent that causes SARS was conclusively identified as a new coronavirus unlike any other known human or animal virus in the coronavirus family. Severe acute respiratory syndrome is a newly emerging infectious disease that is highly contagious with significant morbidity and mortality. It is a form of atypical pneumonia characterised by a high fever $\left(>38^{\circ} \mathrm{C}\right)$, dry cough, breathing difficulties and rapid deterioration, although chills, malaise, myalgia, rigors and headaches may be the main discriminating symptoms in the early stages (Lee et al., 2003). The disease is transmitted by droplet and direct contact (Donnelly et al., 2003).

The rate of deterioration of patients with SARS is also alarmingly high, with many requiring intensive care due to severe desaturation and worsening lung damage in spite of oxygen therapy. This has resulted in patients requiring endotracheal intubation and mechanical ventilation to correct the ventilation-perfusion mismatch.

\section{CONSEQUENCES FOR NURSES, INTENSIVE CARE UNITS AND THE HEALTH CARE SYSTEM}

The health care system, the frontline health care professionals and support staff, and especially the ICUs, have been under extreme pressure to meet the sudden demand arising from SARS. The large number of patients requiring intensive care resulted in demands to double the number of ICU beds. Converting other clinical bed areas into ICU beds was an enormous task, requiring additional equipment and human resources. The Hospital Authority (HA, 2003) has been closely monitoring the need for ICU beds and 
additional medical and nursing manpower requirements, and has been purchasing additional new ventilators and providing crash courses in intensive care to both medical and nursing personnel (HA, 2003).

The pressure on manpower was a problem during this outbreak, coupled with an increasing number of nursing staff being admitted with SARS. The Hospital Authority nurse executives and nurse managers spared no effort in managing the nursing service. Recruitment and deployment of nurses became a necessity. The already limited number of ICU-trained nurses in Hong Kong resulted in deploying nurses from the general ward areas, who had no intensive care training or experience to work in the ICU. Final year nursing students were recruited from three universities to work as Temporary Undergraduate Nursing Students (TUNS) and walk-in centres were established to recruit qualified nurses (Lum, 2003).

Our experience showed that these deployed nurses were very anxious and stressed, not only from the fear of contracting the disease but mostly from feeling incompetent when working in such a high-technology area. These concerns were supported in an interview with nurses working in the ICU (Tsang, 2003) where they described their experience as similar to working in a 'battlefield'. Critical care nurses expressed that they felt exhausted from having to work extra shifts. They were also depressed because they could not see any positive progress in most of their patients, and they had to witness the rapid deterioration of their colleagues who contracted SARS, who were then nursed in their own ICU.

Final year nursing students who worked in SARS-designated areas under the TUNS scheme stated that the experience speeded up their transformation from being a novice to a competent nurse. They also made every effort to learn quickly so as not to be a burden to the other nursing staff in the unit (Wong, 2003). In spite of their fears of contracting the infection, they learned to appreciate the importance of teamwork, good communication, supporting one another, and the satisfaction of caring for others and sacrificing self for the public benefit.

Support to staff in terms of professional guidance and an opportunity for sharing views and experiences is crucial (Thompson, 2003). Effective communication is central to information giving. Reassurance and preparation for unpleasant procedures can help alleviate anxiety by removing the additional burden of facing the unknown (House and Stark, 2002). In order to support the staff, the hospital established a telephone counselling hotline for staff, as well as a training and preceptorship programme for new nurses working in the ICU. On a macro level, tangible supports such as provision of suitable protective equipment, manpower arrangements and paid leave for pregnant nurses were provided (Chan \& Chan, 2003).

The infection among health care providers was a sobering reminder of the importance of adhering to infection control measures. The Hong Kong Department of Health (2003) released a set of updated infection control measures for the home for staff caring for patients with SARS, which were available through their website. All such staff were asked to adopt precautionary measures at home for at least 10 days from the latest contact with SARS patients. These precautionary measures include: frequent hand-washing with liquid soap; putting on surgical masks; avoiding sharing of food, eating utensils and towels; avoiding close contact such as kissing and hugging; and maintaining good home ventilation. Some nurses, however, decided to stay away from their families by living in the staff quarters provided by the hospital. In spite of the negative effects on the nurses, they continued to put their health, their life and their family at risk in order to care for these patients.

The Hong Kong Government, including the Department of Health and the Hospital Authority, adopted widespread public health measures, including travel restrictions and home quarantine. Infection control measures were updated in line with the CDC (2003b) and WHO (2003) guidelines. Patients were isolated in a negative pressure room where possible or in a SARS-ICU or SARS-ward designated area. Pre-existing patients were transferred to other SARS-free centres. Other strategies adopted by the Hospital Authority included recruiting more nurses to needy areas, enforcing strict surveillance and reporting systems, and consulting with hospital engineers regarding ventilation and airflow disturbances. All health care personnel, especially those working in close contact with SARS patients, had to wear the personal protective equipment (Figure 1).

Infection control measures included careful attention to hand washing and hand disinfection with an alcohol-based product,

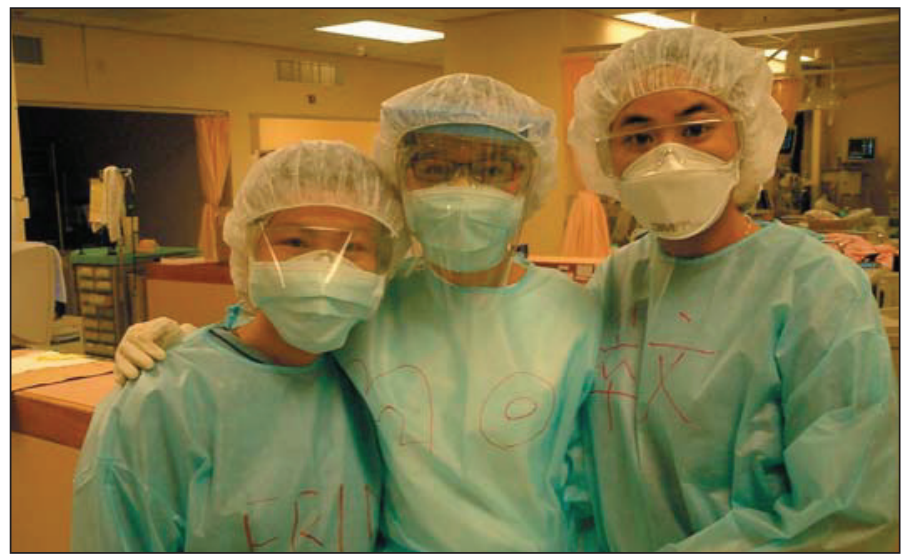

Figure 1: ICU nurses with personal protective equipment.

and the use of quaternary ammonium-based, phenol-based, and alcohol-based disinfectants (Wenzel \& Edmond, 2003). Because recent data suggest that the virus may remain viable on a dry surface for up to 24 hours, frequent surface cleaning of the clinical areas was enforced, and education of all staff with regards to the appropriate infection control measures and the importance of adhering to these guidelines was provided. Other infection control measures enforced were frequent environmental cleaning, cohorting of exposed health care providers to minimize the number of individuals involved, and the restriction of visitors to the general ward areas, with a no visiting policy in ICU (Lopez, Chan \& Wong, 2003). Visiting relatives, if allowed by the health care facility, were kept to a minimum. They were issued with protective equipment, educated on infection control measures and supervised during their visits.

\section{PLANNING FOR FUTURE OUTBREAKS}

The lesson learned was that only one individual was required to start the outbreak and the rapid intercontinental spread was related to travel of unsuspected, asymptomatic individuals who had contact with a person with SARS. Patients with SARS are likely to progress rapidly from mild to severe respiratory failure, requiring prolonged mechanical ventilation and supportive critical care. This has implications in planning for future outbreaks of SARS, which are predicted to re-occur during the winter months. 
Hospital administrators must ensure an increased capacity to treat these patients, and clinicians must have the necessary equipment, protective devices and training in preparation for any future outbreaks.

Strict infection control in the hospital setting is essential for the management of SARS. The infection is highly contagious, spreading by close contact droplet transmission (Seto et al., 2003). However, recent evidence has also shown that the coronavirus in urine and faeces could be a source of infection (Drosten et al., 2003). Infection control measures are now in place and it is mandatory that all health care professionals present documented evidence of successful completion of an infection control module.

The outbreak of SARS also brought various psychological reactions from the public. Nearly $80 \%$ of the 1,002 public surveyed were worried about the spread of the disease to the community; $40 \%$ felt scared and helpless about its spread, while 20\% were concerned about contracting the disease (Tang and Wong, 2003). The Government has launched vigorous public health education programmes to enhance the public's understanding of the disease and the adoption of preventative health measures against SARS. The public is constantly reminded, through posters and media, to remain vigilant in adhering to good personal and environmental hygiene.

\section{CONCLUSION}

The outbreak of SARS has provided a lesson to the people of Hong Kong. The public were touched by the devotion and selflessness of all the health care professionals who battled against SARS and those who donated generously to purchase the much-needed protective equipment. Tribute was also paid to those who died. During the International Nurses Day Ceremony on May 12, 2003 , the Chief Executive of Hong Kong acknowledged all frontline health care workers and affirmed his respect for all nurses and the nursing profession for standing together to fight SARS. Transmission rates fell and no more new cases were detected by the end of June 2003. This was primarily due to a reduced population contact rate, improved hospital infection control and symptomatic individuals seeking early treatment.

In the event of the re-occurrence of SARS, Hong Kong will be ready to meet any challenges. The nursing care of patients will be based on a systematic assessment, planning, implementation and evaluation of evidence-based care. Infection control measures are in place and will be implemented and strictly adhered to. Isolation and quarantine measures will be enforced in some circumstances. Attention will be given to the psychological state of patients, family members and health care workers. Public health education strategies for SARS prevention will continue.

\section{REFERENCES}

Centers for Disease Control and Prevention (CDC). (2003a) Preliminary clinical description of severe acute respiratory syndrome. MMWR Morbidity and Mortality Weekly Report, 52 (12), 255-256.

Centers for Disease Control and Prevention (CDC). (2003b) Updated interim domestic infection control guidance in the health care and community setting for patients with suspected SARS. March 18,

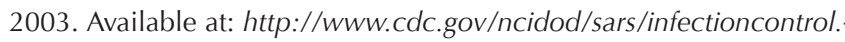
htm. [Accessed 28 June, 2003]

Chan HY \& Chan LW. (2003) Affirming flames: stress management for nurses under SARS outbreak. The Hong Kong Nursing Journal, 39 (1), 21-23.

Department of Health. (2003) Health, Welfare and Food Bureau SARS Bulletin. May 22, 2003. Available at: $h t t p: / / w w w . i n f o . g o v . h k / d h / d i s-$ eases/ap/eng/bulletin0522.pdf [Accessed 23 May 2003].

Donnelly, CA, Ghani, AC, Leung, GM, Hedley, AJ, Fraser, C, Riley S, Abu-Raddad, LJ, Ho, LM, Thach, TQ, Chau, P, Chan, KP, Lam, TH, Tse, LY, Tsang, T, Liu, SH, Kong, JHB, Lau, EM, Ferguson, NM, Anderson, RM. (2003) Epidemiological determinants of spread of causal agent of severe respiratory syndrome in Hong Kong. The Lancet, 361 (9371), 1761-1766.

Drosten, C, Gunther, S, Preiser, W, van der Werf, S, Brodt, HR, Becker, S, Rabenau, H, Panning, M, Kolesniskova, L, Fouchier, AM, Berger, A, Burguire, AM, Cinatl, J, Eickmann, M, Escriou, N, Grywna, K, Kramme, S, Manuguerra, JC, Muller, S, Rickerts, V, Sturmer, M, Vieth, S, Klenk, HD, Osterhaus, AD, Schmitz, H \& Doerr, HW. (2003) Identification of a novel coronavirus in patients with severe acute respiratory syndrome. New England Journal of Medicine, 348 (20), 1967-1976.

Hospital Authority (HA). (2003) Intensive care facilities in public hospitals, April 12. Press Release No. 243. Available at http://www.ha.org.hk/hesd/nsapi [Accessed 21 July 2003].

House, A \& Stark, D (2002) Clinical Review. ABC of

Psychological Medicine: Anxiety in medical patients. British Medical Journal 325 (7357), 207-209

Lee, N, Hui, D, Wu, A, Chan, P, Cameron, P, Joynt, G, Ahuja, A, Yung, MY, Leung, CB, To, KF, Lui, SF, Szeto, CC, Chung, S \& Sung, J. (2003) A major outbreak of severe acute respiratory syndrome in Hong Kong. The New England Journal of Medicine, 348 (20), 1986-1994.

Lopez, V, Chan, KS \& Wong, YC. (2003) Nursing care of patients with severe acute respiratory syndrome in the intensive care unit: case reports in Hong Kong. International Journal of Nursing Studies. (In press) Available online at http://www.sciencedirect.com [Accessed 30 August 2003].

Lum, S. (2003) SARS crisis: united in courage. Pi lota Newsletter, 6 (1), 2. Seto, WH, Tsang, D, Yung, RWH, Ching, TY, Ng, TK, Ho, M, Ho, LM, Peiris, JSM. (2003) Effectiveness of precautions against droplets and contact in prevention of nosocomial transmission of severe acute respiratory syndrome (SARS). The Lancet, 361 (9368), 1519-1520.

Tang, CSK \& Wong, JCY. (2003) Survey results on public responses to atypical pneumonia in Hong Kong. Available at: http://www.cuhk.edu. hk/ipro/pressrelease/030320e.htm [Accessed 18 July, 2003).

Thompson, DR. (2003) SARS - some lessons for nursing (Editorial). Journal of Clinical Nursing, 12 (5), 615-617.

Tomlinson, B \& Cockram, C. (2003) SARS: experience at the Prince of Wales Hospital, Hong Kong. The Lancet, 361 (9368), 1486-1487.

Tsang, AS. (2003) Standing at the frontline. The Hong Kong Nursing Journal, 39 (1), 9-11.

Wenzel, RP \& Edmond, M. (2003) Managing SARS amidst uncertainty. The New England Journal of Medicine, 348 (20), 1947-1948.

Wong, GW \& Hui, DSC. (2003) Severe acute respiratory syndrome (SARS):epidemiology, diagnosis and management (editorial). Thorax, 58 (7), 558-560

Wong, HY. (2003) Transformation from novice. The Hong Kong Nursing Journal, 39 (1), 19.

World Health Organisation (WHO). (2003) Hospital infection control guidance for severe acute respiratory syndrome, March 16, 2003. Available at: http://www.who.int/csr/sars/infectioncontrol/en/ [Accessed 20 July 2003]. 